\title{
Understanding the Voltammetry of Bulk CO Electrooxidation in Neutral Media through Combined SECM Measurements
}

\author{
Mariana C. O. Monteiro, Leon Jacobse, and Marc T. M. Koper* \\ Cite This: J. Phys. Chem. Lett. 2020, 11, 9708-9713 \\ Read Online
}

ACCESS |

山ll Metrics \& More

Article Recommendations

Supporting Information

ABSTRACT: Recently, the bulk electrooxidation of $\mathrm{CO}$ on gold or platinum has been used to detect $\mathrm{CO}$ produced during $\mathrm{CO}_{2}$ reduction in neutral media. The $\mathrm{CO}$ bulk oxidation voltammetry may show two distinct peaks depending on the reaction conditions, which up to now have not been understood. We have used scanning electrochemical microscopy (SECM) to probe $\mathrm{CO}$ oxidation and $\mathrm{pH}$ in the diffusion layer during $\mathrm{CO}_{2}$ reduction. Our results show that the two different peaks are due to diffusion limitation by two different species, namely, $\mathrm{CO}$ and $\mathrm{OH}^{-}$. We find that between $\mathrm{pH} 7$ and $11, \mathrm{CO}$ oxidation by water and $\mathrm{OH}^{-}$gives rise to the first and second peak observed in the voltammetry, respectively. Additional rotating disc experiments showed that specifically in this $\mathrm{pH}$ range the current of the second peak is diffusion limited by the $\mathrm{OH}^{-}$concentration, since it is lower than the $\mathrm{CO}$ concentration.

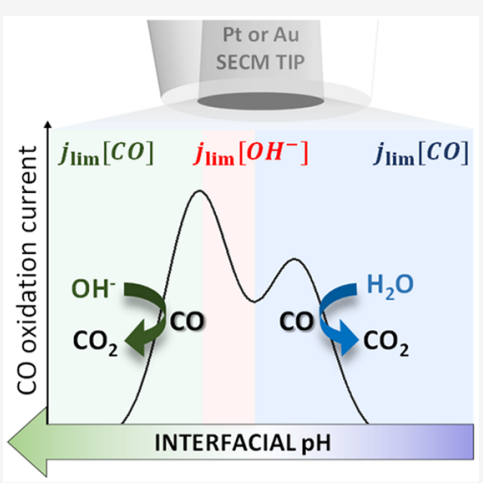

$\mathrm{T}$ he electrochemical oxidation of $\mathrm{CO}$ on gold $^{1-4}$ and platinum $^{5-9}$ has been widely studied, especially in terms of how $\mathrm{pH}$ and surface structure affect the reaction. ${ }^{10-12}$ Recently, CO oxidation on these two surfaces has been used in rotating ring disc electrodes (RRDE), ${ }^{13-15}$ scanning electrochemical microscopy (SECM), ${ }^{16,17}$ and cyclic voltammetry ${ }^{18}$ experiments for in situ probing the products of $\mathrm{CO}_{2}$ reduction (CO2R) or the interfacial $\mathrm{pH}$. In these studies, mostly carried out in neutral media, two distinct or convoluted peaks have been observed in the $\mathrm{CO}$ oxidation voltammetry, ${ }^{13,14,16-18}$ but their assignment is unclear. While the oxidation of a $\mathrm{CO}$ adlayer has been extensively studied on mono and polycrystalline platinum at different $\mathrm{pH}$, there are no reports elucidating the mechanism of $\mathrm{CO}$ bulk oxidation on platinum in neutral media. These conditions are of special interest as the typical $\mathrm{CO} 2 \mathrm{R}$ reaction environment.

In general, the electrochemical oxidation of $\mathrm{CO}$ is believed to take place through a Langmuir-Hinshelwood ( $\mathrm{LH})$ mechanism, similar to the gas phase reaction. It is proposed that an adsorbed $\mathrm{CO}$ is oxidized by a nearest-neighbor oxygencontaining species. The oxygen donor is generally believed to be $\mathrm{OH}_{\mathrm{ad}}$ from water in acidic (eq 1 ) or from $\mathrm{OH}^{-}$in alkaline (eq 2) media, respectively. ${ }^{19}$

$$
\begin{aligned}
& \mathrm{H}_{2} \mathrm{O} \rightarrow \mathrm{OH}_{\mathrm{ad}}+\mathrm{H}^{+}+\mathrm{e}^{-} \\
& \mathrm{OH}^{-} \rightarrow \mathrm{OH}_{\mathrm{ad}}+\mathrm{e}^{-} \\
& \mathrm{CO}_{\mathrm{ad}}+\mathrm{OH}_{\mathrm{ad}} \rightarrow \mathrm{CO}_{2}+\mathrm{H}^{+}+\mathrm{e}^{-}
\end{aligned}
$$

Especially on gold electrodes, previous work has shown that $\mathrm{CO}$ oxidation takes place at higher overpotentials in acidic than in alkaline media. ${ }^{3}$ As studies on bulk $\mathrm{CO}$ oxidation have previously been carried out only in strongly acidic or alkaline conditions, there is currently no consistent explanation for the coexistence of two peaks in the bulk $\mathrm{CO}$ electrooxidation voltammetry in neutral media.

Using platinum cyclic voltammetry to determine CO2R products is a relatively new approach. Narayanaru et al. ${ }^{16}$ used a platinum ultramicroelectrode (Pt-UME) in the substrate generation-tip collection (SG-TC) mode of SECM to probe the products of $\mathrm{CO} 2 \mathrm{R}$ on gold in $0.1 \mathrm{M} \mathrm{KHCO}_{3}$ electrolyte. Two distinct $\mathrm{CO}$ oxidation peaks were observed in the PtUME voltammetry when the gold sample was held at $-1.3 \mathrm{~V}$ vs $\mathrm{Ag} / \mathrm{AgCl}$. Although a shift in the $\mathrm{CO}$ oxidation peak potential was observed as a function of sample roughness, and attributed to interfacial $\mathrm{pH}$ changes, the nature of the two different $\mathrm{CO}$ oxidation peaks was not discussed. In the same work, $\mathrm{CO}$ oxidation on gold directly after CO2R was also performed, and two distinct anodic peaks were observed in the $\mathrm{CO}$ oxidation region. The authors attributed the peak at more positive potential to the oxidation of $\mathrm{CO}$ and the peak at less positive potential to the oxidation of methanol. Recently, Zhang and $\mathrm{Co}^{13}$ reported the use of a RRDE with CO2R performed on a gold disc while oxidation of the reaction products is carried out on a platinum ring. A broad $\mathrm{CO}$ oxidation peak is observed on the platinum ring, which seems

Received: September 13, 2020

Accepted: October 21, 2020 
actually a convolution of two different peaks. The broadness of the peak was explained by the presence of bubbles and was not further discussed. In the same work, $\mathrm{CO}$ oxidation was carried out on the polycrystalline $\mathrm{Pt}$ ring in $\mathrm{CO}$ saturated $0.1 \mathrm{M}$ $\mathrm{KHCO}_{3}$ at $\mathrm{pH} 6.8$ and 9.2. At $\mathrm{pH} 9.2$ two distinct peaks were observed and attributed to $\mathrm{CO}$ oxidation taking place at $\{100\}$ facets and $\{111\}$ facets of the Pt-UME.

In order to better understand bulk $\mathrm{CO}$ oxidation in the $\mathrm{CO} 2 \mathrm{R}$ reaction environment, we have used a Pt-UME in the SG-TC mode of SECM while CO2R was carried out at a gold substrate. Using a functionalized gold $\mathrm{pH}$ sensor, we have used SECM to measure the $\mathrm{pH}$ in the diffusion layer under the same reaction conditions and approximately the same tip-to-surface distance. $^{20}$ The correlation of these results and additional rotating disc electrode ( $\mathrm{RDE}$ ) measurements provide a clear understanding on the nature of the two different $\mathrm{CO}$ oxidation peaks previously observed ${ }^{13,14,16-18}$ and how they are influenced by the interfacial $\mathrm{pH}$. Our measurements show the nature of the oxygen donor as a function of $\mathrm{pH}$ and how in a narrow $\mathrm{pH}$ window the diffusion of these species and not (only) the diffusion of $\mathrm{CO}$ itself is what limits the current of the oxidation reaction and gives rise to the specific voltammetry. We emphasize that $\mathrm{CO}$ diffusion in this paper refers to $\mathrm{CO}$ bulk diffusion, not to $\mathrm{CO}$ surface diffusion as it has been studied in $\mathrm{CO}$ stripping experiments. ${ }^{10,11}$

SECM CO Oxidation Measurements. To probe CO oxidation while $\mathrm{CO} 2 \mathrm{R}$ and the competing hydrogen evolution (HER) are taking place at the gold sample, a Pt-UME $(6.5 \pm 0.07 \mu \mathrm{m}$ radius) is used. A schematic representation of the experiment is shown in Figure 1a. The blank and CO stripping cyclic voltammetry $(\mathrm{CV})$ of the Pt-UME can be seen in Figure 1c. After characterization of the Pt-UME, a capacitive approach $^{20,21}$ is performed in air in order to determine the tipto-surface distance. Figure 1d shows a measured approach curve (data points) together with its fit (line). Details on the capacitive approach curve measurement and fitting are available in the Supporting Information. To minimize the influence of the tip in the diffusion process, it was placed at a relatively large distance of $40 \pm 3 \mu \mathrm{m}$ from the surface.

During CO2R, the composition of the reaction interface changes significantly due to $\mathrm{OH}^{-}$generation. Consequently, the local $\mathrm{pH}$ depends on the sample potential. In order to investigate the nature of the two distinct peaks in the bulk $\mathrm{CO}$ oxidation voltammetry, we have created different $\mathrm{CO} 2 \mathrm{R}$ reaction environments around the $\mathrm{Pt}-\mathrm{UME}$ by using an unbuffered electrolyte $\left(0.1 \mathrm{M} \mathrm{Cs}_{2} \mathrm{SO}_{4}, \mathrm{pH}=3\right)$ and changing the potential at which the reaction is carried out at the gold substrate.

The Pt-UME voltammetry is constantly recorded while chronoamperometry at the sample is carried out at different potentials. The chronoamperometry data from the gold sample can be found in Figure S4. Figure 2 shows the results obtained at different sample potentials. Ten cycles of the Pt-UME were recorded, and the 10th cycle is displayed. It can be seen that at low sample potentials (Figure $2 \mathrm{a}$ ) only hydrogen is produced at the gold sample as the tip voltammetry shows features characteristic of hydrogen oxidation (HOR). ${ }^{22}$ The HOR current increases when going from -0.1 to $-0.3 \mathrm{~V}$ but stops increasing between -0.3 and $-0.4 \mathrm{~V}$ likely due to diffusion limitation of the proton reduction reaction taking place at the surface. At these potentials, no strong $\mathrm{pH}$ gradients are expected and bicarbonate is present only in trace amounts, as the $\mathrm{p} K_{\mathrm{a}}$ of the $\mathrm{CO}_{2(\mathrm{aq})}+\mathrm{H}_{2} \mathrm{O} \leftrightarrow \mathrm{HCO}_{3}{ }^{-}+\mathrm{H}^{+}$equilibrium a)

$\mathrm{CO} / \mathrm{H}_{2}$ probe

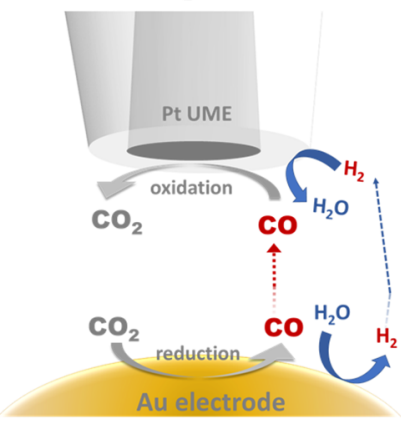

c)

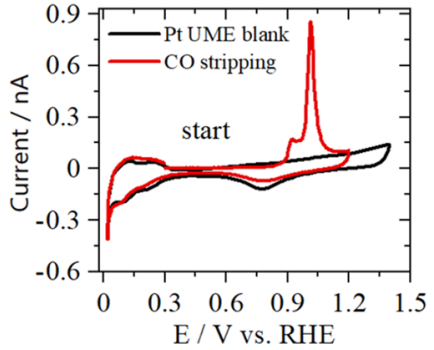

b)

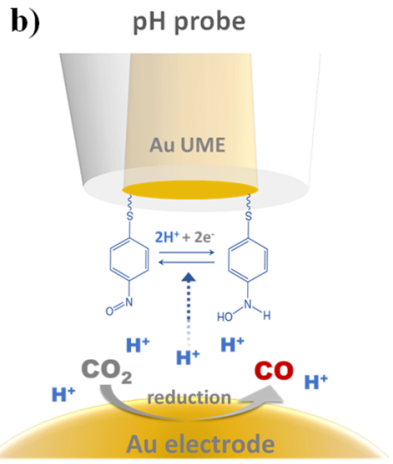

d)

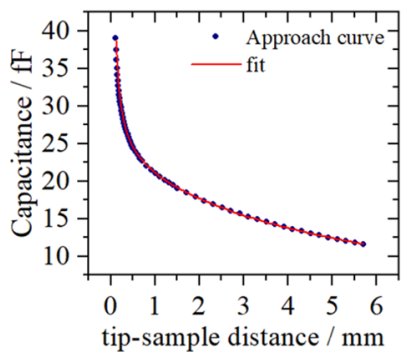

Figure 1. Schematic representation of (a) the SG-TC collection mode of SECM, where a Pt-UME is used to probe $\mathrm{CO}$ and $\mathrm{H}_{2}$ while $\mathrm{CO}_{2}$ reduction takes place at the gold sample, (b) the functionalized $\mathrm{Au}-$ UME used to measure $\mathrm{pH}$, and (c) Pt-UME blank voltammetry (black) taken in argon-saturated $0.1 \mathrm{M} \mathrm{H}_{2} \mathrm{SO}_{4}$ and $\mathrm{CO}$ stripping voltammetry measured in the same electrolyte after exposing the Pt$\mathrm{UME}$ to a $\mathrm{CO}$ atmosphere for $5 \mathrm{~min}$. CVs taken at $200 \mathrm{mV} \mathrm{s}^{-1}$. (d) Capacitive approach curve to determine the absolute tip-to-surface distance.

reaction is 6.4. At $-0.5 \mathrm{~V}$ (sample potential) CO starts being formed. This leads to the poisoning of the Pt-UME for HOR, and a small $\mathrm{CO}$ oxidation peak appears in the forward scan (see Figure 2b). This peak gradually increases and shifts slightly positive going from -0.5 to $-0.65 \mathrm{~V}$, due to a higher concentration of $\mathrm{CO}$ in solution. For simplicity, from now on we will call this "peak I". In the backward scan, a peak due to HOR is still observed at sample potentials -0.5 and $-0.55 \mathrm{~V}$, which decreases due to the increase in $\mathrm{CO}$ concentration. At -0.6 and $-0.65 \mathrm{~V}$ only current due to bulk $\mathrm{CO}$ oxidation is seen at the Pt-UME voltammetry and a subtle shoulder appears, which we will call "peak II". The shape of the CO oxidation $\mathrm{CV}$ with the hysteresis between forward and backward scans is typical for bulk $\mathrm{CO}$ oxidation on $\mathrm{Pt}$ and is discussed in detail elsewhere. ${ }^{23}$

Figure $2 \mathrm{c}$ shows results obtained at sample potentials of -0.7 and $-0.75 \mathrm{~V}$. At $-0.7 \mathrm{~V}$ the $\mathrm{CO}$ oxidation peak shows a clear shoulder in the Pt-UME voltammetry at $0.45 \mathrm{~V}$ vs Ag/ $\mathrm{AgCl}$ due to an increase of peak II. At $-0.75 \mathrm{~V}$ peak II gradually increases while peak I decreases. Here, three subsequent Pt-UME CVs are plotted to show this peak I/ peak II transition. This transition suggests a strong change in the reaction environment when $-0.75 \mathrm{~V}$ is applied to the gold sample. If the rate of $\mathrm{OH}^{-}$production becomes higher than the rate at which bicarbonate can be formed, the alkalinity near the surface will increase and the concentration of $\mathrm{OH}^{-}$will become larger than the concentration of $\mathrm{HCO}_{3}^{-}$. The coexistence of peak I and peak II strongly suggests that two different mechanisms for $\mathrm{CO}$ oxidation are taking place simultaneously as a function of the reaction environment, i.e., 
a)

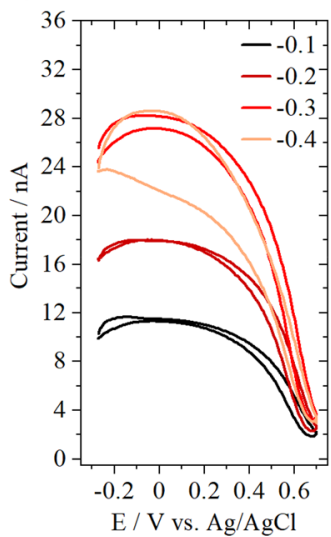

b)

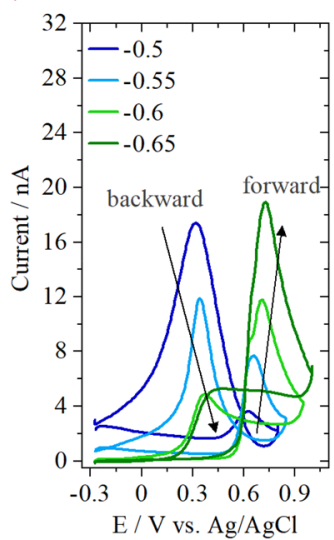

c)

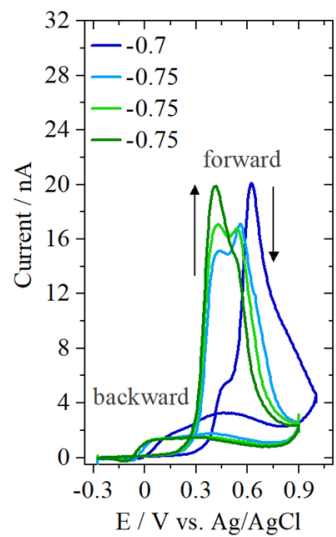

d)

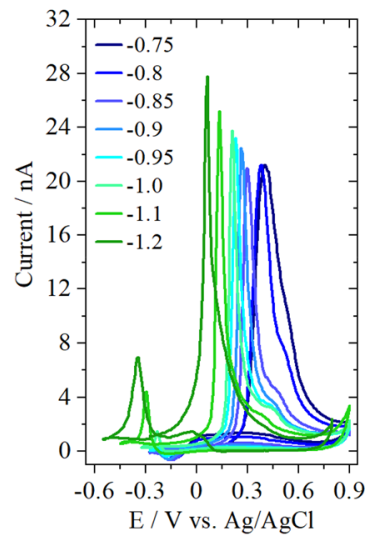

Figure 2. Pt-UME voltammetry recorded in $0.1 \mathrm{M} \mathrm{Cs}_{2} \mathrm{SO}_{4}\left(200 \mathrm{mV} \mathrm{s}{ }^{-1}, \mathrm{pH}=3\right)$ while $\mathrm{CO}_{2} \mathrm{R}$ and/or $\mathrm{HER}$ take place at the gold sample at potentials (a) from -0.1 to $-0.4 \mathrm{~V}$, (b) from -0.5 to $-0.65 \mathrm{~V}$, (c) from -0.7 to $-0.75 \mathrm{~V}$, and (d) from -0.75 to $-1.2 \mathrm{~V}$. The gold sample potentials shown in the legend are reported versus the reversible hydrogen electrode.

$\mathrm{OH}^{-}$concentration. At more negative sample potentials, it can be seen in the Pt-UME voltammetry (Figure $2 \mathrm{~d}$ ) that peak I is still present but gradually becomes less pronounced. Peak II shifts to more negative potentials, likely due to an increase in local alkalinity. At $-1 \mathrm{~V}$ sample potential, a small peak appears in the backward scan at $-0.23 \mathrm{~V}$ vs $\mathrm{Ag} / \mathrm{AgCl}$ due to hydrogen oxidation.

To better understand the mechanism behind bulk $\mathrm{CO}$ oxidation and the diffusion processes taking place, the currents of peak I and peak II are evaluated separately by holding the gold sample at potentials where either peak I or peak II are present $(-0.65$ and $-0.9 \mathrm{~V}$ vs $\mathrm{RHE})$. By varying the scan rate at which the Pt-UME voltammetry is recorded, we can gain insights into the nature of the species participating in the reaction and limiting the current, as the peak current can be calculated following the Randles-Sevcik equation: ${ }^{24}$

$$
i_{\mathrm{p}}=2.69 \times 10^{5} \times n^{3 / 2} \times A \times D^{1 / 2} \times C \times \nu^{1 / 2}
$$

where $n$ is the number of electrons transferred, $A$ is the electrode surface area, $D$ is the diffusion coefficient of the reacting species that limits the current, $C$ is its concentration, and $\nu$ is the scan rate. The peak current plotted as a function of the square root of the scan rate can be seen in Figure 3. The

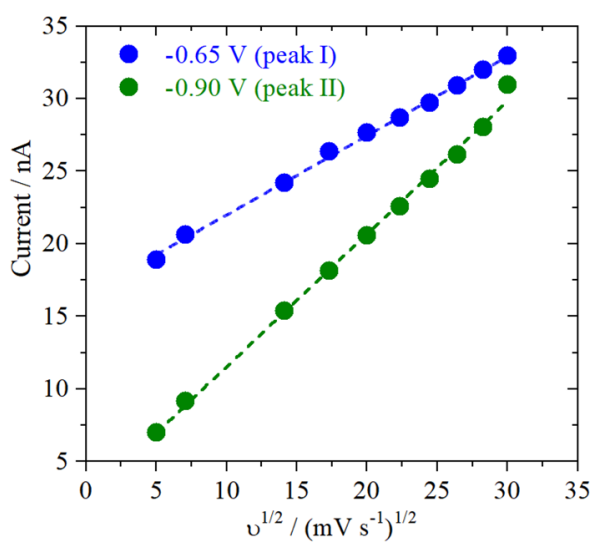

Figure 3. Scan rate dependency of the $\mathrm{CO}$ oxidation peak current measured at the Pt-UME. Measurements were performed at two different sample potentials in order to evaluate separately the $\mathrm{CO}$ oxidation peak I (blue) and peak II (green). two different slopes found indicate that the reaction is limited by the diffusion of two different species, giving rise to the two observed peaks in the voltammetry. However, derivation of the diffusion coefficient for identification of the species is not possible here, as the exact concentration of the reactants is unknown.

SECM pH Measurements. To gain better insights into the reaction interface when these two peaks coexist, SECM $\mathrm{pH}$ measurements were performed under the same conditions as the previously shown $\mathrm{H}_{2} / \mathrm{CO}$ oxidation experiments. Here, the tip is a functionalized gold ultramicroelectrode (Au-UME) $\mathrm{pH}$ sensor. As can be seen in the scheme in Figure $1 \mathrm{~b}$ the gold surface is modified with a self-assembled monolayer containing the hydroxylaminothiophenol/4-nitrosothiophenol redox couple. The $\mathrm{pH}$ sensing is realized by recording the tip cyclic voltammetry and monitoring the Nernstian shift of the midpeak potential. Details on the sensor fabrication and data processing can be found in our previous work. ${ }^{20}$ The Au-UME is positioned at the same distance from the surface as the PtUME $(40 \pm 3 \mu \mathrm{m})$ and the tip voltammetry is recorded while changing the sample potential. The $\mathrm{pH}$ measurements in time can be found in Figure S5.

The measured $\mathrm{pH}$ as a function of sample potential is displayed in Figure 4 together with the peak potential of the

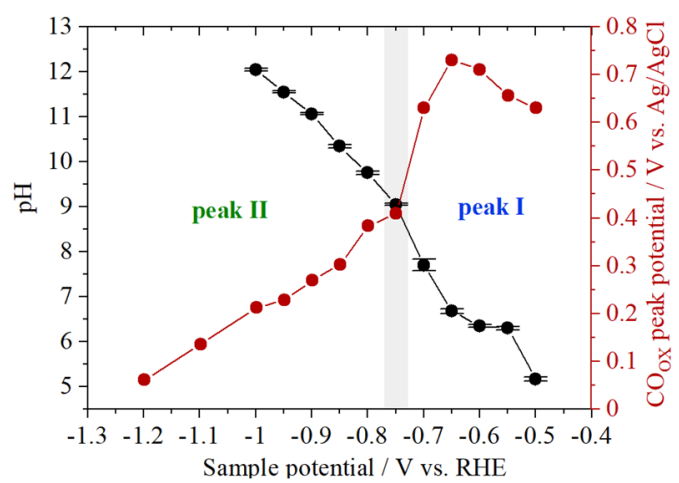

Figure 4. Correlation between the $\mathrm{pH}$ measurements performed with a functionalized Au-UME (black circles) with the $\mathrm{CO}$ oxidation peak position extracted from the measurements performed with the PtUME (red circles) during $\mathrm{CO}_{2}$ reduction on gold $\left(0.1 \mathrm{M} \mathrm{Cs}_{2} \mathrm{SO}_{4}, \mathrm{pH}\right.$ $=3, \mathrm{CO}_{2}$ saturated). 

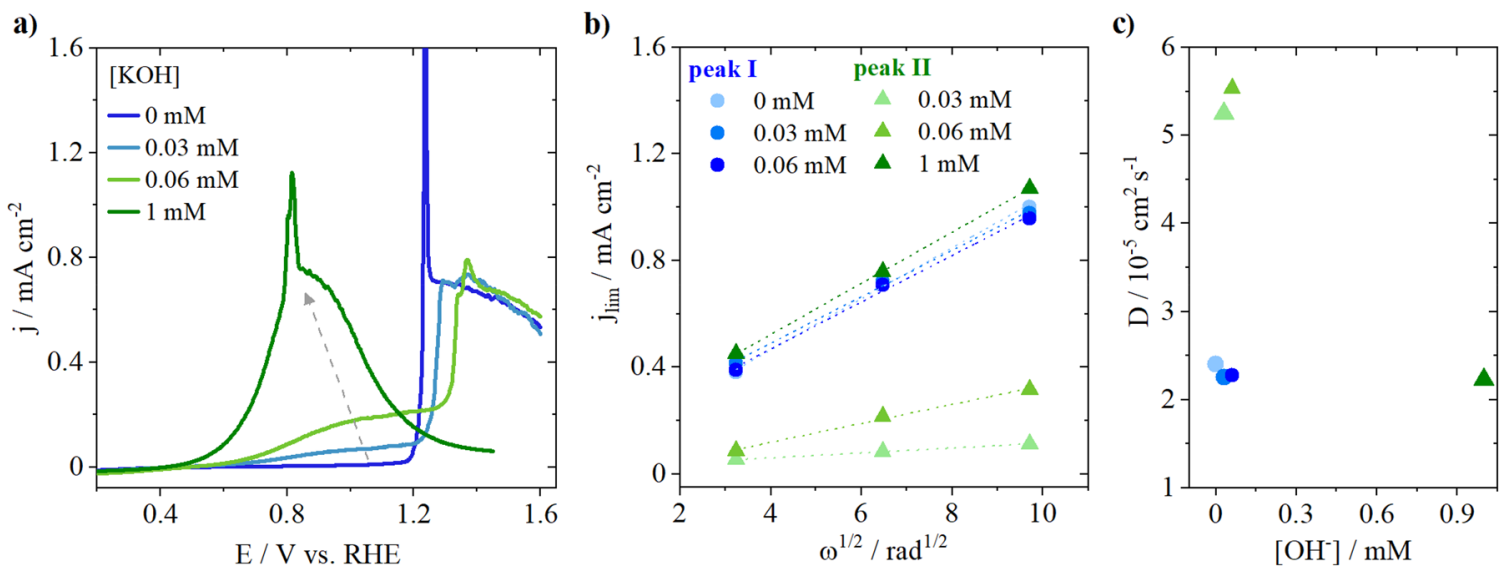

Figure 5. RDE CO oxidation measurements on a polycrystalline $\mathrm{Pt}$ disc in $\mathrm{Cs}_{2} \mathrm{SO}_{4}(\mathrm{pH}=7.2)$ performed at $400 \mathrm{rpm}$ with a $25 \mathrm{mV} \mathrm{s} \mathrm{s}^{-1} \mathrm{scan}$ rate. (a) Reaction performed in the presence of different concentrations of $\mathrm{KOH},(\mathrm{b})$ Levich plot, and (c) derivation of the diffusion coefficients for peak I (blue circles) and peak II (green triangles).

$\mathrm{CO}$ oxidation peaks from Figure 2. At low sample potentials neither the $\mathrm{pH}$ increases nor the $\mathrm{CO}$ oxidation peak I shifts negatively. In this potential range the $\mathrm{CO}_{2(\mathrm{aq})} \leftrightarrow \mathrm{HCO}_{3}^{-}$ equilibrium buffers the interfacial $\mathrm{pH}$, the value of which remains near the $\mathrm{p} K_{\mathrm{a}}$ of the equilibrium reaction (6.4). At $-0.75 \mathrm{~V}$ sample potential, where the transition between peak I and peak II is observed (Figure 2c), there is an increase in $\mathrm{pH}$ from 7.7 to 9 and the $\mathrm{CO}$ oxidation peak also starts to shift negatively. The correlation shown in Figure 4 suggests that peak I exists at neutral $\mathrm{pH}$ and, therefore, that water is the oxygen donor for $\mathrm{CO}$ oxidation. As peak II appears when the buffer breaks down and the interface becomes more alkaline, it seems that peak II corresponds to $\mathrm{CO}$ being oxidized by $\mathrm{OH}^{-}$. However, these findings still do not elucidate why different slopes were found in Figure 3, which suggest that the current of peak I and II is limited by two different species, which could be $\mathrm{OH}^{-}, \mathrm{CO}$, or $\mathrm{HCO}_{3}{ }^{-}$.

$R D E$ Measurements. In order to assign the species leading to the diffusion limiting current observed for peaks I and II, we performed rotating disk electrode (RDE) experiments using a polycrystalline platinum disk. The blank voltammetry of the platinum electrode is seen in Figure S6. Figure 5 displays the results obtained in pure $0.1 \mathrm{M} \mathrm{Cs}_{2} \mathrm{SO}_{4}(\mathrm{pH}=7.2)$ and when $0.03,0.06$, and $1 \mathrm{mM} \mathrm{KOH}$ were added to the electrolyte, leading to $\mathrm{pH} 9.5,9.8$, and 11 , respectively. The electrolyte is saturated with $\mathrm{CO}$ during all the measurements, leading to a constant $\mathrm{CO}$ concentration of $1 \mathrm{mM}$. Figure 5a shows the voltammetry of bulk $\mathrm{CO}$ oxidation in the different electrolytes taken at $400 \mathrm{rpm}$. In pure $\mathrm{Cs}_{2} \mathrm{SO}_{4}$ (neutral $\mathrm{pH}$ ) only one diffusion limiting plateau is seen between 1.2 and $1.6 \mathrm{~V}$ vs RHE, corresponding to peak I previously observed in the SECM measurements. When $0.03 \mathrm{mM} \mathrm{KOH}$ is added to the electrolyte, two plateaus are observed, one with a similar current as before, between 1.2 and $1.6 \mathrm{~V}$ vs RHE, and another with a lower diffusion limiting current, between 0.8 and $1.2 \mathrm{~V}$ vs $\mathrm{RHE}$ (peak II). Increasing the $\mathrm{OH}^{-}$concentration leads to an increase in the diffusion limiting current of peak II, confirming the correlation found in the SECM measurements between peak II and $\mathrm{pH}$. At $\mathrm{pH} 11(1 \mathrm{mM} \mathrm{KOH})$, only one peak is observed at lower overpotentials, with a current matching the one found at $\mathrm{pH}$ 7.2. To elucidate which species causes the diffusion limitation in each condition, measurements were also performed at different rotation rates (see Figure S7). The Levich equation describes the relationship between the diffusion limiting current and the rotation rate and can be used to derive the diffusion coefficient of the species leading to the diffusion limitation: ${ }^{24}$

$$
j_{\lim }=0.62 n F D^{2 / 3} \nu^{-1 / 6} C \omega^{1 / 2}
$$

where $n$ is the number of electrons transferred, $F$ is the Faraday constant, $D$ is the diffusion coefficient of the species, $\nu$ is the kinematic viscosity of the solvent, $C$ is the concentration of the species, and $\omega$ is the rotation rate. The diffusion limiting currents obtained at the different rotations for the plateaus corresponding to peak I and II are shown in Figure $5 \mathrm{~b}$ as a function of the square root of the rotation rate. The diffusion coefficients are derived from the slopes obtained in Figure $5 b$ and are displayed in Figure 5c. It can be seen that for peak I the same slope is found in pure $\mathrm{Cs}_{2} \mathrm{SO}_{4}$ and in the presence of 0.03 and $0.06 \mathrm{mM} \mathrm{OH}^{-}$. The calculated diffusion coefficients all approximate the theoretical value reported for CO $(2.03 \times$ $10^{-5} \mathrm{~cm}^{2} \mathrm{~s}^{-1}$ ), confirming that the current of peak I is limited by the diffusion of $\mathrm{CO}^{25}$ In the case of peak II, interestingly a different slope is found as a function of the $\mathrm{OH}^{-}$ concentration. When the $\mathrm{OH}^{-}$concentration is lower than the $\mathrm{CO}$ concentration $(1 \mathrm{mM})$, a slope of approximately $5.5 \times$ $10^{-5} \mathrm{~cm}^{2} \mathrm{~s}^{-1}$ is found based on the $\mathrm{OH}^{-}$concentration, corresponding to the value reported for $\mathrm{OH}^{-}$ions $(5.23 \times$ $\left.10^{-5} \mathrm{~cm}^{2} \mathrm{~s}^{-1}\right) .{ }^{25}$ This clearly shows that, in this $\mathrm{pH}$ range, $\mathrm{OH}^{-}$ is not only the oxygen donor but also the species whose transport limits the reaction. When the $\left[\mathrm{OH}^{-}\right]=[\mathrm{CO}]=1$ $\mathrm{mM}$, the slope found is similar to the one of peak $\mathrm{I}$ and derivation of the diffusion coefficient based on the $\mathrm{CO}$ concentration again matches the value reported in literature for $\mathrm{CO}$. The latter implies that at $\mathrm{pH} 11$ or higher only one peak is present and that the current is limited by the diffusion of $\mathrm{CO}$. Based on the two different SECM measurements and the RDE results, we can now build a clear understanding of the nature of the two peaks observed during bulk $\mathrm{CO}$ electrooxidation in neutral media. As summarized in Table 1, at acidic and neutral $\mathrm{pH}, \mathrm{OH}^{-}$is present in small concentrations and $\mathrm{CO}$ is oxidized by water. The current is limited by the concentration of $\mathrm{CO}$ in solution and only one peak is observed in the voltammetry at high overpotential, namely, peak I. Between $\mathrm{pH} 7$ and 11, two peaks coexist in the $\mathrm{CO}$ oxidation voltammetry, namely, peak I and peak II. Peak II appears at lower overpotentials than peak I and is due to $\mathrm{CO}$ oxidation by $\mathrm{OH}^{-}$. The current is limited by 
Table 1. Relationship between $\mathrm{pH}, j_{\text {lim }}$ Species, and the Bulk CO Electrooxidation Voltammetry

\begin{tabular}{llcl}
\multicolumn{1}{c}{$\mathrm{pH}$} & O-donor & $j_{\text {lim }}$ species & \multicolumn{1}{c}{ voltammetry } \\
$\leq 7$ & $\mathrm{H}_{2} \mathrm{O}$ & $\mathrm{CO}$ & peak I \\
$11>\mathrm{pH}>7$ & $\mathrm{H}_{2} \mathrm{O}, \mathrm{OH}^{-}$ & $\mathrm{OH}^{-}$ & peak I + peak II \\
$\geq 11$ & $\mathrm{OH}^{-}$ & $\mathrm{CO}$ & peak II \\
\hline
\end{tabular}

the $\mathrm{OH}^{-}$concentration. Above $\mathrm{pH} \mathrm{11}$, only peak II is present due to $\mathrm{CO}$ oxidation by $\mathrm{OH}^{-}$, and the current is limited again by the concentration of $\mathrm{CO}$, which becomes smaller than the $\mathrm{OH}^{-}$concentration in this $\mathrm{pH}$ range. Even though methanol has been previously observed as a product of $\mathrm{CO}_{2}$ reduction on roughened gold electrodes, ${ }^{16}$ we can exclude that methanol oxidation gives rise to peak II. We have analyzed the CO2R products formed in the conditions of this study (flat gold electrode, $0.1 \mathrm{M} \mathrm{Cs}_{2} \mathrm{SO}_{4}, \mathrm{pH}=3$ ) with online chromatography (Figure S8). The only products detected are hydrogen and $\mathrm{CO}$, at potentials for which peak I and II are observed.

Summarizing, in the present work we have used SECM in SG-TC mode in order to probe $\mathrm{CO}$ oxidation on a Pt-UME while $\mathrm{CO}_{2} \mathrm{R}$ to $\mathrm{CO}$ takes place on a gold sample. By changing the local reaction environment, we could observe the existence of two distinct peaks in the $\mathrm{CO}$ oxidation voltammetry as a function of $\mathrm{pH}$. SECM local $\mathrm{pH}$ measurements were also performed demonstrating a clear correlation between the $\mathrm{OH}^{-}$ concentration and the coexistence of the two distinct $\mathrm{CO}$ oxidation peaks. Additional RDE measurements confirmed that the peaks coexist in a narrow $\mathrm{pH}$ range in which the $\mathrm{OH}^{-}$ concentration is smaller than the $\mathrm{CO}$ concentration (between $\mathrm{pH} 7$ and 11), which results in two diffusion-limited current regimes. It is now clear why these two peaks are mainly observed when probing $\mathrm{CO}_{2}$ reduction, ${ }^{13,14,16-18}$ as the $\mathrm{pH}$ in the $\mathrm{CO}_{2}$ reduction reaction environment usually lies in between the $\mathrm{CO}_{2} / \mathrm{HCO}_{3}{ }^{-} \mathrm{pK}$ a and more alkaline values that develop according to the current density and buffer capacity of the electrolyte used. Considering the increased number of publications where $\mathrm{CO}$ oxidation is being used to probe $\mathrm{CO}_{2}$ reduction, we hope our work provides the basis for the correct assignment of the two distinct peaks often observed in the $\mathrm{CO}$ oxidation voltammetry.

\section{EXPERIMENTAL METHODS}

SECM Measurements. SECM experiments were carried out in our home-built SECM setup, which was previously described in detail. ${ }^{20}$ All the equipment and cleaning procedures used here are exactly the same as reported in our previous work. The procedures for preparing the platinum ultramicroelectrode and functionalized gold $\mathrm{pH}$ sensor are available in the SI. The sample used is a gold disc (0.5 mm thick, MaTeck, 99.995\%) cleaned and polished with diamond suspension using a protocol described elsewhere. ${ }^{26}$ For all measurements, the tip-to-surface distance was determined by performing a capacitive approach in air. ${ }^{20}$ Details are found in the Supporting Information (see eq S2). Measurements were performed in $5 \mathrm{~mL}$ of $0.1 \mathrm{M} \mathrm{Cs}_{2} \mathrm{SO}_{4}$ (Alfa Aesar, Puratronic, 99.997\%, metals basis) which was constantly purged with $\mathrm{CO}_{2}$. The electrolyte choice was made based on the high activity for $\mathrm{CO}_{2}$ reduction achieved in $\mathrm{Cs}^{+}$-containing electrolytes. Measurements were performed at a constant distance from the surface, and the tip voltammetry was constantly recorded at a scan rate of $200 \mathrm{mV} \mathrm{s}^{-1}$ while the sample potential was varied.
RDE Measurements. RDE experiments were performed using a MSR Electrode Rotator (Pine Research Instrumentation) equipped with a AFE6M shaft. The working electrode was a platinum disc $(5.0 \mathrm{~mm}$ OD $\times 4.0 \mathrm{~mm}$ thick, Pine Research and Instrumentation) and the counter electrode a platinum mesh. Further experimental details are found in the Supporting Information.

\section{ASSOCIATED CONTENT}

\section{(s) Supporting Information}

The Supporting Information is available free of charge at https://pubs.acs.org/doi/10.1021/acs.jpclett.0c02779.

Experimental details of the SECM and RDE experiments, characterization of the ultramicroelectrodes, $\mathrm{pH}$ sensor fabrication, capacitive approach, chronoamperometry and $\mathrm{pH}$ data, blank voltammetry of the Pt disc electrode, and $\mathrm{CO} 2 \mathrm{R}$ product analysis (PDF)

\section{AUTHOR INFORMATION}

\section{Corresponding Author}

Marc T. M. Koper - Leiden Institute of Chemistry, Leiden University, 2300 RA Leiden, The Netherlands; (1) orcid.org/ 0000-0001-6777-4594; Email: m.koper@lic.leidenuniv.nl

\section{Authors}

Mariana C. O. Monteiro - Leiden Institute of Chemistry, Leiden University, 2300 RA Leiden, The Netherlands; (1) orcid.org/0000-0001-7451-1004

Leon Jacobse - DESY NanoLab, Deutsches Elektronensynchrotron DESY, D-22607 Hamburg, Germany; (1) orcid.org/0000-0002-2825-0963

Complete contact information is available at:

https://pubs.acs.org/10.1021/acs.jpclett.0c02779

\section{Notes}

The authors declare no competing financial interest.

\section{ACKNOWLEDGMENTS}

This work was supported by the European Commission under contract no. 722614 (Innovative Training Network Elcorel).

\section{REFERENCES}

(1) Kita, H.; Nakajima, H.; Hayashi, K. Electrochemical Oxidation of $\mathrm{CO}$ on $\mathrm{Au}$ in Alkaline Solution. J. Electroanal. Chem. Interfacial Electrochem. 1985, 190 (1-2), 141-156.

(2) Rodriguez, P.; Garcia-Araez, N.; Koper, M. T. M. Self-Promotion Mechanism for CO Electrooxidation on Gold. Phys. Chem. Chem. Phys. 2010, 12 (32), 9373-9380.

(3) Rodriguez, P.; Koper, M. T. M. Electrocatalysis on Gold. Phys. Chem. Chem. Phys. 2014, 16 (27), 13583-13594.

(4) Rodriguez, P.; Plana, D.; Fermin, D. J.; Koper, M. T. M. New Insights into the Catalytic Activity of Gold Nanoparticles for CO Oxidation in Electrochemical Media. J. Catal. 2014, 311, 182-189.

(5) Grgur, B. N.; Marković, N. M.; Lucas, C. A.; Ross, P. N. Electrochemical Oxidation of Carbon Monoxide: From Platinum Single Crystals to Low Temperature Fuel Cells Catalysts. Part I: Carbon Monoxide Oxidation onto Low Index Platinum Single Crystals. J. Serb. Chem. Soc. 2001, 66 (11-12), 785-797.

(6) Kita, H.; Shimazu, K.; Kunimatsu, K. Electrochemical Oxidation of $\mathrm{CO}$ on $\mathrm{Pt}$ in Acidic and Alkaline Solutions. Part I. Voltammetric Study on the Adsorbed Species and Effects of Aging and $\mathrm{Sn}$ (IV) Pretreatment. J. Electroanal. Chem. Interfacial Electrochem. 1988, 241 (1-2), 163-179. 
(7) Abe, K.; Uchida, H.; Inukai, J. Electro-Oxidation of $\mathrm{CO}$ Saturated in $0.1 \mathrm{M} \mathrm{HClO}_{4}$ on Basal and Stepped Pt Single-Crystal Electrodes at Room Temperature Accompanied by Surface Reconstruction. Surfaces 2019, 2 (2), 315-325.

(8) Park, I. S.; Chen, D. J.; Atienza, D. O.; Tong, Y. J. Enhanced CO Monolayer Electro-Oxidation Reaction on Sulfide-Adsorbed $\mathrm{Pt}$ Nanoparticles: A Combined Electrochemical and in Situ ATRSEIRAS Spectroscopic Study. Catal. Today 2013, 202 (1), 175-182.

(9) Wang, H.; Abruña, H. D. Origin of Multiple Peaks in the Potentiodynamic Oxidation of CO Adlayers on Pt and Ru-Modified Pt Electrodes. J. Phys. Chem. Lett. 2015, 6 (10), 1899-1906.

(10) Lai, S. C. S.; Lebedeva, N. P.; Housmans, T. H. M.; Koper, M. T. M. Mechanisms of Carbon Monoxide and Methanol Oxidation at Single-Crystal Electrodes. Top. Catal. 2007, 46 (3-4), 320-333.

(11) García, G.; Koper, M. T. M. Carbon Monoxide Oxidation on Pt Single Crystal Electrodes: Understanding the Catalysis for Low Temperature Fuel Cells. ChemPhysChem 2011, 12 (11), 2064-2072.

(12) Gisbert, R.; García, G.; Koper, M. T. M. Oxidation of Carbon Monoxide on Poly-Oriented and Single-Crystalline Platinum Electrodes over a Wide Range of PH. Electrochim. Acta 2011, 56 (5), 24432449.

(13) Zhang, F.; Co, A. C. Direct Evidence of Local PH Change and the Role of Alkali Cation during $\mathrm{CO} 2$ Electroreduction in Aqueous Media. Angew. Chem. 2020, 132, 1691.

(14) Zhang, F.; Co, A. C. Rapid Product Analysis for the Electroreduction of $\mathrm{CO}_{2}$ on Heterogeneous and Homogeneous Catalysts Using a Rotating Ring Detector. J. Electrochem. Soc. 2020, 167 (4), 046517.

(15) Goyal, A.; Marcandalli, G.; Mints, V. A.; Koper, M. T. M. Competition between $\mathrm{CO}_{2}$ Reduction and Hydrogen Evolution on a Gold Electrode under Well-Defined Mass Transport Conditions. J. Am. Chem. Soc. 2020, 142 (1), 4154.

(16) Narayanaru, S.; Chinnaiah, J.; Phani, K. L.; Scholz, F. PH Dependent CO Adsorption and Roughness-Induced Selectivity of $\mathrm{CO}_{2}$ Electroreduction on Gold Surfaces. Electrochim. Acta 2018, 264, 269-274.

(17) Sreekanth, N.; Phani, K. L. Selective Reduction of $\mathrm{CO}_{2}$ to Formate through Bicarbonate Reduction on Metal Electrodes: New Insights Gained from SG/TC Mode of SECM. Chem. Commun. 2014, 50 (76), 11143-11146.

(18) Lee, C. W.; Cho, N. H.; Nam, K. T.; Hwang, Y. J.; Min, B. K. Cyclic Two-Step Electrolysis for Stable Electrochemical Conversion of Carbon Dioxide to Formate. Nat. Commun. 2019, 10 (1), 1-8.

(19) McPherson, I. J.; Ash, P. A.; Jones, L.; Varambhia, A.; Jacobs, R. M. J.; Vincent, K. A. Electrochemical CO Oxidation at Platinum on Carbon Studied through Analysis of Anomalous in Situ IR Spectra. J. Phys. Chem. C 2017, 121 (32), 17176-17187.

(20) Monteiro, M. C. O.; Jacobse, L.; Touzalin, T.; Koper, M. T. M. Mediator-Free SECM for Probing the Diffusion Layer $\mathrm{PH}$ with Functionalized Gold Ultramicroelectrodes. Anal. Chem. 2020, 92 (2), 2237-2243.

(21) de Voogd, J.M.; van Spronsen, M.A.; Kalff, F.E.; Bryant, B.; Ostojic, O.; den Haan, A.M.J.; Groot, I.M.N.; Oosterkamp, T.H.; Otte, A.F.; Rost, M.J. Fast and Reliable Pre-Approach for Scanning Probe Microscopes Based on Tip-Sample Capacitance. Ultramicroscopy 2017, 181, 61-69.

(22) Sheng, W.; Zhuang, Z.; Gao, M.; Zheng, J.; Chen, J. G.; Yan, Y. Correlating Hydrogen Oxidation and Evolution Activity on Platinum at Different $\mathrm{PH}$ with Measured Hydrogen Binding Energy. Nat. Commun. 2015, 6, 6-11.

(23) Koper, M. T. M.; Schmidt, T. J.; Marković, N. M.; Ross, P. N. Potential Oscillations and S-Shaped Polarization Curve in the Continuous Electro-Oxidation of $\mathrm{CO}$ on Platinum Single-Crystal Electrodes. J. Phys. Chem. B 2001, 105 (35), 8381-8386.

(24) Bard, A. J.; Faulkner, L. R. Electrochemical Methods. Fundamentals and Applications, 2nd ed.; John Wiley \& Sons: 2001.

(25) Haynes, W. M. Handbook of Chemistry and Physics, 95th ed.; CRC Press: New York, 2014.
(26) Monteiro, M. C. O.; Koper, M. T. M. Alumina Contamination through Polishing and Its Effect on Hydrogen Evolution on Gold Electrodes. Electrochim. Acta 2019, 325, 134915. 